\title{
Approach and driving data for assessing the pollutant emissions at a street level
}

\author{
M. André ${ }^{1}$, S. Hausberger ${ }^{2}$ \& H. Steven ${ }^{3}$ \\ ${ }^{1}$ INRETS - Transport and Environment Laboratory \\ ${ }^{2}$ Graz University of Technology, Austria \\ ${ }^{3}$ RWTÜV Fahrzeug GmbH, Germany
}

\begin{abstract}
In the frame of the ARTEMIS and COST346 European research projects, an approach has been designed for estimating the pollutant emissions from the road transport at a street level. This requires defining the traffic situations encountered in the European context considering the actual practices and the road network hierarchical organisation. The approach requires appropriated emissions factors and driving related data. For the passenger cars, reference emissions are derived from a typology of the numerous European driving cycles in 15 tests patterns. This cartography is used to compute linearly the emissions of a given traffic situation. For the heavy-duty vehicles, an instantaneous emission model is used to derive the emission for each vehicle category and traffic situation. In both cases, driving data (i.e. speed curves) are needed to represent each traffic situation. A large collection of the existing European data recorded on-board vehicles was managed with that aim. Although this is a high quantity of data, the identification of specific and representative speed curves remained difficult. The broad lines of this approach are recapitulated in this paper.

Keywords: road network, traffic condition, vehicle, passenger car, heavy duty vehicle, speed, pollutant emission, fuel consumption.
\end{abstract}

\section{Introduction}

More and more, the estimation of the pollutant emissions from the road transport is needed at a low spatial scale (i.e. in one street, as a function of the traffic conditions) to enable detailed inventories or impact studies. Indeed pollutant 
emissions are generally quite sensitive to different "traffic situations", as the encountered driving conditions significantly vary.

In the frame of ARTEMIS (Assessment and reliability of transport emission models and inventory systems. Project funded by the European Commission within the $5^{\text {th }}$ Framework Research Program, DG TREN) and of COST346 (Emissions and Fuel Consumption from Heavy Duty Vehicles. European Cooperation in the Field of Scientific and Technical Research) projects, which intend at renewing the European emission estimation tools, it was considered that an approach at a low scale (street level) or "traffic situation approach" was necessary and requested by the users. However, such an approach has different implications:

- It is necessary to develop a pertinent structure in traffic situations, understandable across the different countries and users, and preferably close to the classifications usually implemented by the traffic engineers.

- It is then necessary to estimate the pollutant emissions for each of these newly defined traffic situations.

- Furthermore, such a detailed structure implies a large need of data (driving data) for each of the situations.

Works have then been conducted in these aims [1,2], which enabled the design of a satisfying and agreed structure in traffic situations, relying on the road functions and existing classifications, as well as the taking into account of complementary parameters (traffic conditions, sinuosity, gradient, speed limits) taking into account the actual data and practices throughout Europe.

Apart from these "structural" aspects deliberately oriented to the actual practices and to the potential users of the emissions estimation tools, an approach for estimating the emissions for each traffic situation was designed for passenger cars and an instantaneous model was derived for the heavy duty vehicles. Both approaches require speed curves as input data. A collection of the available data throughout Europe was then initiated, as well as it's processing.

\section{Traffic situation definition}

The estimation of the pollutant emissions at a street level implies the definition of "traffic situations" which should be understandable across the different countries and users, and preferably close to the classifications usually implemented by traffic engineers [2]. The definition concerns also the road characteristics (sinuosity, gradient, speed limit, etc.) and the traffic conditions.

A road classification should distinguish urban and rural according to a "morphological" point of view (i.e. continuity of the buildings around a centre and coherence) or to a functional point of view (Functional Urban Area), as mobility and traffic are to a large extent linked to these contexts. It was proposed to adopt a road classification according to the function (access/distribution/through) and to the road network hierarchical organization (Fig. 1, [3]). The distinction between motorway and normal road and the road characteristics were then considered according to the most usual practices in Europe to propose an agreed urban and rural road typology (Tables 1 and 2). 


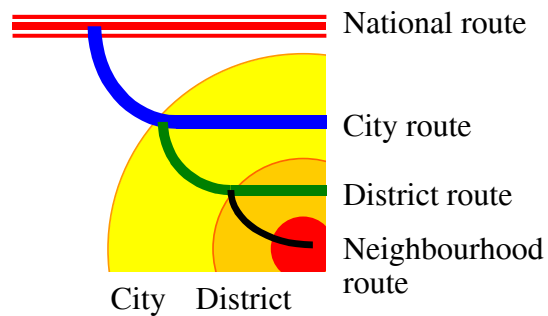

Figure 1: Hierarchisation of the road network.

Table 1: $\quad$ Urban roads typology.

\begin{tabular}{|l|l|c|}
\hline Main function & Characteristics & $\begin{array}{l}\text { Speed limit } \\
(\mathrm{km} / \mathrm{h})\end{array}$ \\
\hline \multirow{2}{*}{$\begin{array}{l}\text { National and regional network - Through- } \\
\text { traffic }\end{array}$} & 5a - Motorway & $80-130$ \\
\cline { 2 - 3 } $\begin{array}{l}\text { Agglomeration primary network - Primary } \\
\text { distributor }\end{array}$ & 4b - Non-motorway & $70-100$ \\
\cline { 2 - 3 } & 4b - Non-motorway & $60-110$ \\
\hline Districts distributor & 3 - Road & $50-90$ \\
\hline Local distributor- Inner exchange, local traffic & 2 - Road & $50-60$ \\
\hline Access road - Local traffic. & 1 - Road, side road, etc. & $30-50$ \\
\hline
\end{tabular}

Table 2: $\quad$ Rural roads typology.

\begin{tabular}{|l|l|c|}
\hline Main function & Characteristics & $\begin{array}{l}\text { Speed limit } \\
(\mathrm{km} / \mathrm{h})\end{array}$ \\
\hline $\begin{array}{l}\text { National and regional network - Through and } \\
\text { distribution }\end{array}$ & 5 - Motorway & $80-150$ \\
\cline { 2 - 3 } & 4 - Trunk road & $60-110$ \\
\hline Distributor & 3 - Road & $50-100$ \\
\hline Local distributor - Inner exchange, local traffic & 2 - Road & $50-80$ \\
\hline Access road - Local traffic & 1 - Road, side road, etc. & $30-50$ \\
\hline
\end{tabular}

The road gradient and sinuosity (due to their influence on the HDV emissions and fuel consumption) should also be considered. For large scale estimation, a qualitative approach was proposed (Flat - sinuous / non-sinuous, Hilly - ramps / sinuous, Mountainous). Indeed, a gradient value (i.e. 4\%) has a sense for a short road section but not for one entire trip or a road network. Because of the poor information about the sinuosity and gradient as regards driving, these parameters are only considered for rural roads.

For a good coverage of the actual traffic conditions, a structure in 4 levels was proposed (Fig. 2), with free-flow traffic (average speed at $85-100 \%$ of the free speed), heavy traffic (constraint speed at $65-85 \%$ of the free speed), unsteady quite saturated traffic (variable speed with possible stops in the range of 30 to $60 \%$ of the free speed) and the stop-and-go (speed in the range of 10 $\mathrm{km} / \mathrm{h})$. 


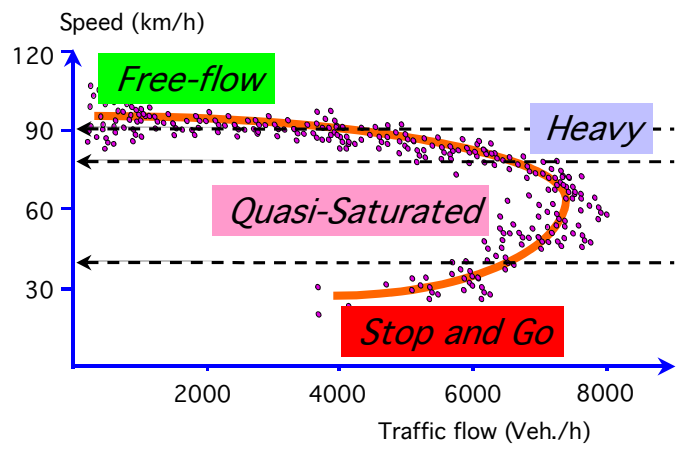

Figure 2: $\quad$ Traffic conditions as regards speed and traffic flow.

\section{Representative speed data}

Apart from the traffic situation definition, the estimation approach requires speed data characterizing each of the traffic situations. A large collection of the existing European data recorded on-board vehicles was managed in that aim.

\subsection{Passenger cars}

Existing driving data were analysed when it was well documented In all, more than 1500 speed versus time curves were considered, but most often, the information on the traffic condition was not available. Few data was available for rural, hilly and mountainous situations. The available speed data were affected to the different traffic situations according to the background information (Fig. 3). This affectation was validated considering the driving statistics (average speed, stop number, etc.) and by comparison between similar situations (coherency).

This process enabled a direct affectation of about 70 cases amongst more than 400. For the other cases, an affectation by similarity was done (i.e. congestion for 2 roads with close speed limits should be comparable, etc.). However, this lack of data remains the main weakness of the approach.

\subsection{Heavy duty vehicles}

In-use European driving data for HDV was available from an international survey conducted to derive a world-wide harmonised engine test cycle for the certification procedure. This database includes

- 13 rigid trucks with gross vehicle mass (GVM) between 5.6 and 28 tons,

- 11 trailer/semi-trailer trucks with GVM between 28 and 40 tons,

- 7 urban buses (standard and articulated) and 1 coach.

For all vehicles, the vehicle speed, acceleration, engine speed and engine power were recorded at each second. For several vehicles the vehicle load was known. 

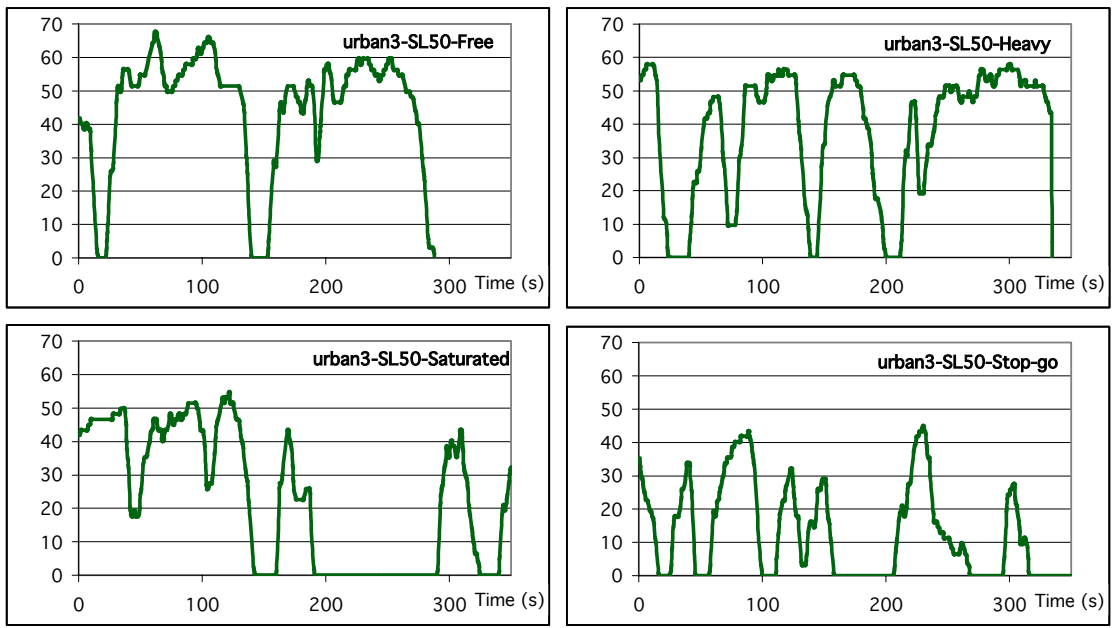

Figure 3: $\quad$ Speed curves for an urban road, speed limit $50 \mathrm{~km} / \mathrm{h}$.
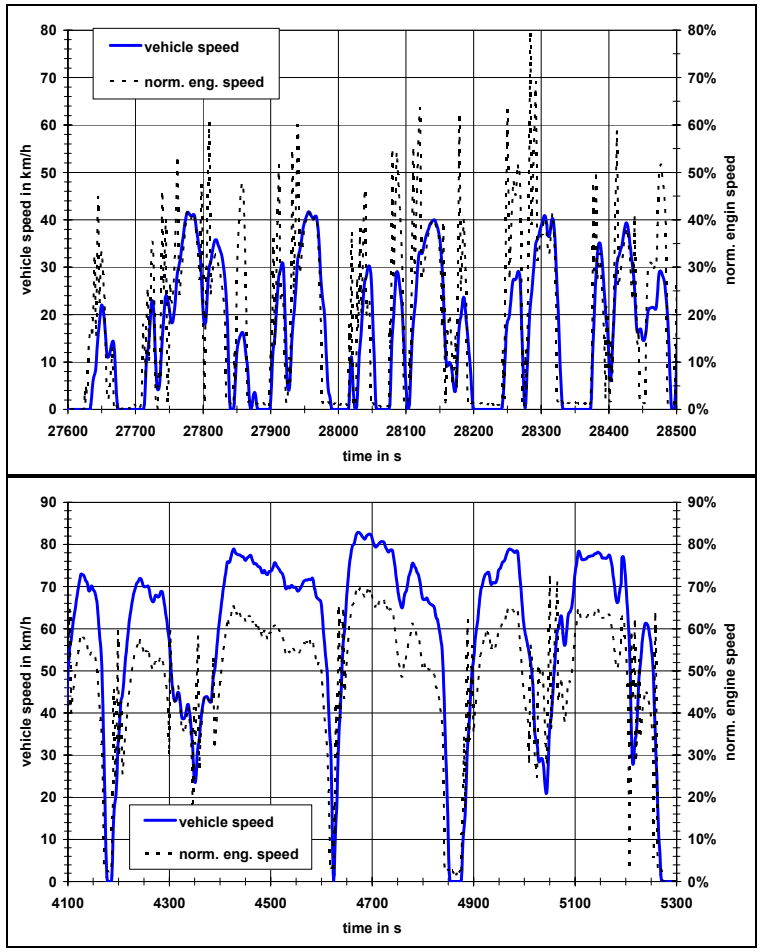

Figure 4: $\quad$ Speed patterns for an urban road, speed limit $40 \mathrm{~km} / \mathrm{h}$ (top) and a rural road, speed limit $80 \mathrm{~km} / \mathrm{h}$ (bottom). 
The altitude recording did not enable to derive reliable road gradient. Therefore, when the mass was known and constant, the road gradient was derived from the difference of the measured engine power for a given driving condition and the power calculated for this driving condition and a flat road. This provided quite good results for rural roads and motorways.

No information related to the road type and characteristics. The following approach was then applied to affect appropriate vehicle speed pattern: the vehicle speed, the engine speed (normalized as regards the rated speed, i.e. $100 \%$ and the idle speed, i.e. $0 \%$ ), the engine load (normalized by dividing the actual power by the maximum power, available at the actual engine speed), and the road gradient (where possible) were plotted versus time. Vehicle speed patterns were then separated into "homogeneous" parts representing a particular road type/traffic situation (Fig. 4). To cluster the speed patterns, the following parameters were calculated:

- the average speed with and without stops, the percentiles of the speed distribution, the percentage of stop time, number of stops per km,

- the percentage of time and distance in acceleration, the average acceleration, and of the acceleration multiplied by the vehicle speed (i.e. the power to mass ratio needed for acceleration) and percentiles of these 2 parameters.

These parameters were then classified and clustered. Appropriate speed patterns were then assigned to the different traffic situations and validated as regards average speed values and stop rates.

\section{Emission estimation approach for the passenger cars}

The Artemis project has enabled the collection of a large number of car emission data (2800 cars, 27,000 vehicle $\mathrm{x}$ test cycle), using more than 800 different driving cycles. In spite of its richness this heterogeneous dataset required a correction as regards the driving cycle. An approach was developed in that aim, which consists in the building-up of a typology of test patterns to aggregate similar test cycles and the calculation of reference emissions [4].

We consider the most significant driving cycles, (i.e. 98 cycles/sub-cycles representing the actual driving conditions and for which there are a significant number of emission data) to elaborate this typology, the other cycles being classified afterwards. The cycles are described through the 2-dimensional time distribution of the instant speed and acceleration. A Binary Correspondence Analysis and an automatic clustering enable the building-up of a typology, maximizing the cycle homogeneity within- and the contrast between- classes. Within these classes or Reference Test Patterns, one or several Reference Test Cycle(s) are selected (as regards their representativity and number of emission data). Thirteen of these cycles are combination of Artemis cycles [5]/sub-cycles. The 2 other cases represent the very congested driving and the stabilized motorway driving in the range of $100 \mathrm{~km} / \mathrm{h}$ (Fig. 5).

After the exclusion of the incoherent or deviating cycles (systematic under or over-estimation), 11000 tests (3100 Diesel, 7700 Petrol) are retained for the elaboration of the references emissions (Fig. 6). 


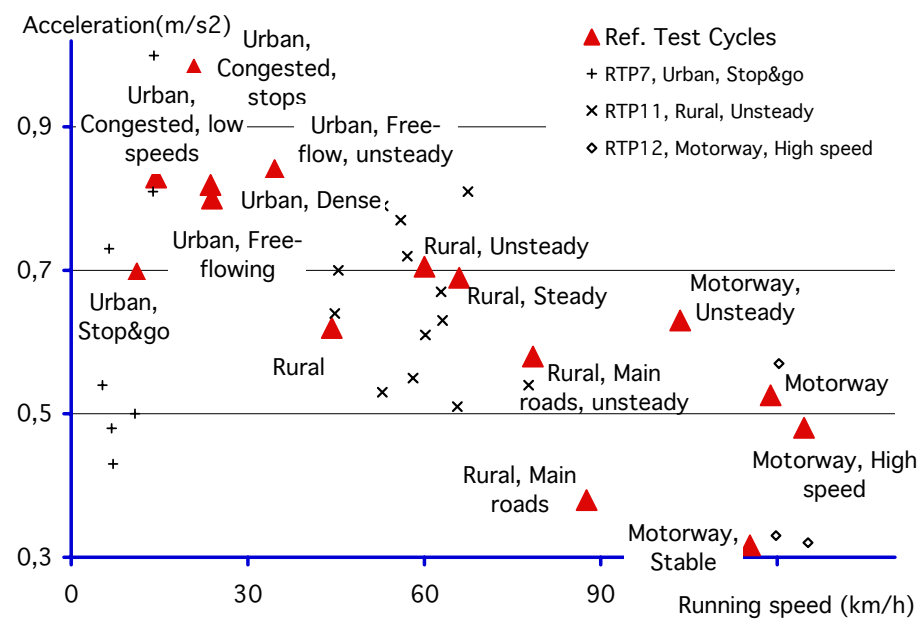

Figure 5: References cycles coverage as regards speed and acceleration.

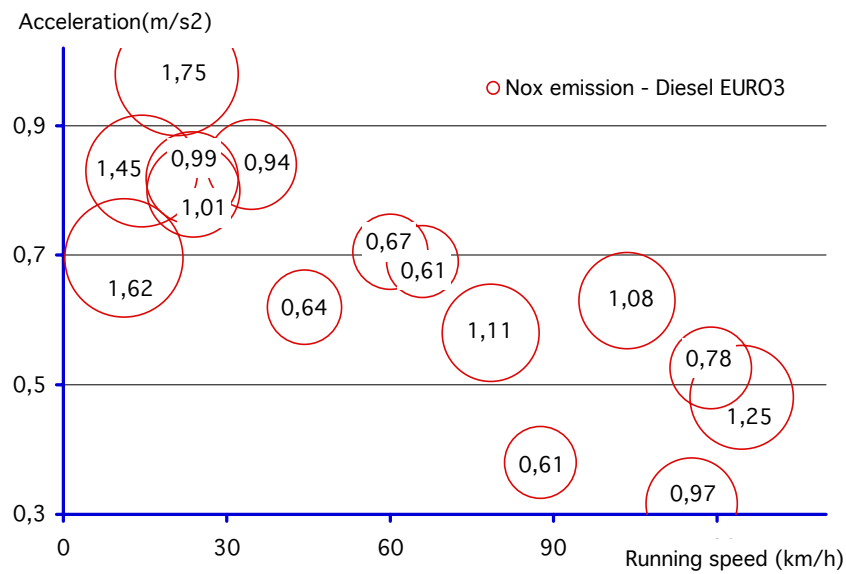

Figure 6: NOx EURO3 Diesel reference emissions.

This process (computation of the emission per driving pattern) is a robust approach as it relies on contrasted driving conditions and considers the cycles according to their quality. It seems then pertinent to build-up emissions functions while starting from this basis. Furthermore, the cartography of the test cycles constitutes a good mapping of the driving conditions as regards the average speed and acceleration, i.e. the dynamic of the traffic conditions. Indeed, we clearly identify two classes of driving along the speed scale, i.e. the stable or normal driving with low acceleration and stop frequencies on one side, and the unsteady driving on the opposite. This distinction should enable a more accurate analysis of the traffic dynamic (Fig. 7). 
These concepts were then implemented to estimate the emissions at the street level. Considering the speed curves for each of traffic situation and computing their speed $\mathrm{x}$ acceleration distribution, we analyse the traffic situations as regards the factorial space elaborated from the driving cycles. By measuring distances from one traffic situation to the 15 reference test cycles, we compute its emission by linear combination of the reference emissions of the closest reference cycles. This interpolation approach enables then the emission estimation for hundreds of traffic situations as regards the reference emissions (Fig. 8).

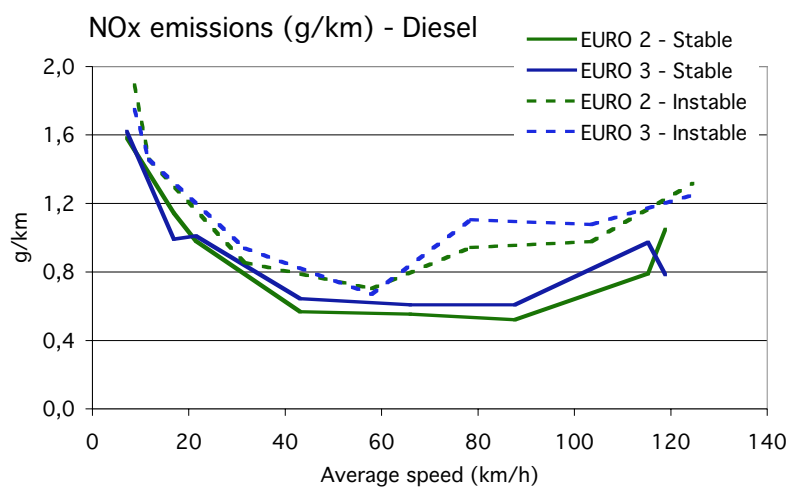

Figure 7: Dynamic influence on the NOx Diesel emissions.

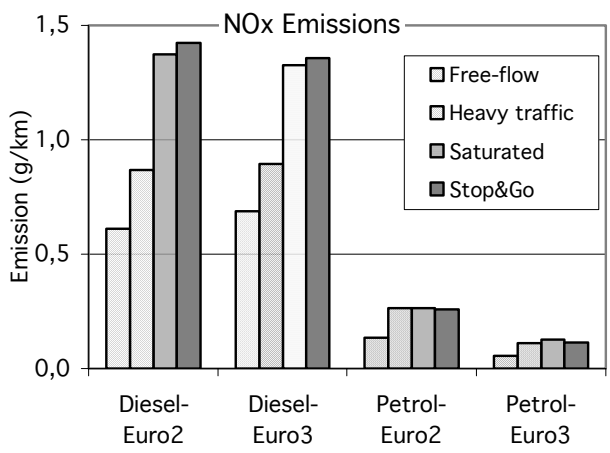

Figure 8: Estimation of the car NOx emissions for an urban trunk road, speed limit $50 \mathrm{~km} / \mathrm{h}$.

\section{Emission estimation approach for the heavy duty vehicles}

The aim of these works was then to elaborate a model capable of simulating accurate emission factors for all types of HDV for various vehicle loadings and within different traffic situations, from engine test emission data.

The model PHEM [6] for the simulation of HDV emission factors computes for given vehicle speed and road gradient curves, the necessary engine power 
according to the driving resistances and losses in the transmission system. The actual engine speed is simulated by the transmission ratios and a driver's gearshift model. The actual emission level is then interpolated from engine emission maps. The resulting steady state emission is corrected by using transient correction functions (Fig. 9).

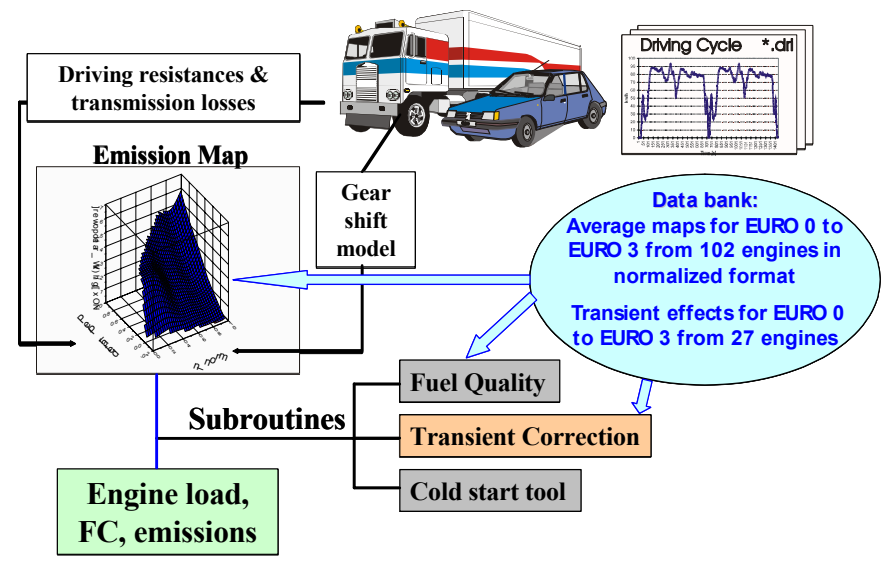

Figure 9: $\quad$ Schematic picture of the model PHEM.

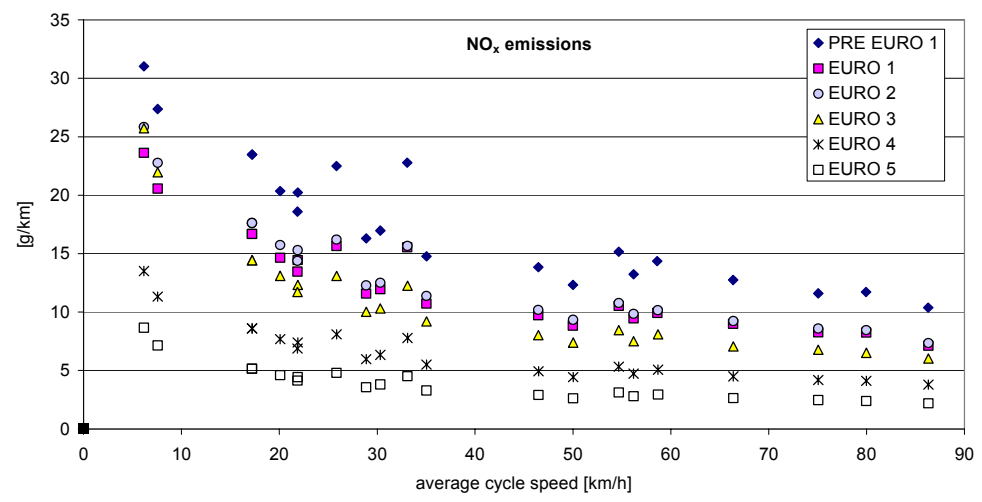

Figure 10: NOx-emission estimation for truck trailers and articulated trucks 34 to 40 tons, $50 \%$ loaded, for different traffic situations without gradient.

Emission tests from 102 engines were collected or measured, representing the most extensive HDV emission database in Europe. These steady state engine emission maps were based on an extended number of test points. The empirical transient correction functions (EURO 0 to 3) were elaborated from 27 engines, for which at least 3 different transient tests and steady state emission maps were available [6]. Fuel quality and cold start tools were also developed. 
Averaged emission maps have been elaborated for the EURO 0 to EURO 5 engines. The relevant vehicle characteristics have been collected by vehicle type, maximum allowed gross weight and loading factor, allowing then the detailed simulation of HDV fleet emissions for any traffic situation with a high accuracy.

Fig. 10 highlights the estimation of the pollutant emissions from different HDV categories within various traffic situations. The EURO 2 and EURO-1 NOx emissions are quite similar, while the EURO-3 vehicles record lower emissions. The trend depends however on the driving cycle: on fast highway cycles, EURO-3 is approximately $20 \%$ below EURO-2, in slow stop \& go traffic the NOx-emission levels of EURO 2 and EURO 3 engines are nearly equal.

\section{Conclusion}

An approach was designed for estimating the pollutant emissions from the vehicles at a street level, implying the elaboration of a traffic situation scheme, which mainly relies on the usual practices in traffic engineering. Specific emission estimation methods were developed for the cars and the heavy-duty vehicles. The required representative speed curves were derived from the collection and analysis of the available European driving data. However, the lack of speed data remains the main weakness of the traffic situation approach, which should be reserved for very local applications.

\section{Acknowledgements}

These works were carried out with the financial support of the European Commission DG TREN and of the COST European authorities.

\section{References}

[1] Poize, N.: Driving Statistics for the Assessment of Pollutant Emissions from Road Transport. INRETS report LTE0221, Bron, France, 94p. 2002.

[2] Fantozzi C., André M., Adra N.: Development of a new approach for the estimation of the pollutant emissions from the road transport at the street level. In: Procs. of the 14th Int. Symp. on Transport and Air Pollution, Graz, Austria, 1-3 June 2005. VKM-THD Mitteilungen, p. 289-298.

[3] ARTISTS: Arterial Streets for people. Final Report. ARTISTS research project (www.tft.lth.se/artists). Ed: Ase Svensson, 104p. 2004.

[4] André M., M. Rapone, R. Joumard et al.: Analysis of the car pollutant emissions as regards driving cycles and kinematic parameters. INRETS report, Bron, nLTE06yy, 140 p., to be published, 2006.

[5] André M.: The ARTEMIS European driving cycles for measuring car pollutant emissions. Sc. of the Tot. Envir., n³34-335, p. 73-84, 2004.

[6] Rexeis M., Hausberger S., Riemersma I., Tartakovsky L., Zvirin Y., Cornelis E.: Heavy Duty vehicle Emissions - Final COST346/ARTEMIS Report. Inst. for Int. Comb. Engines and Thermodynamics; TU Graz, 2005 . 